\title{
Serendipity hints at a non-linear thinking mechanism
}

\author{
Tam-Tri Le \\ Centre for Interdisciplinary Social Research \\ Phenikaa University, Hanoi, Vietnam
}

2 December 2021

Note: The arguments in this short paper should be considered speculative due to limited supporting empirical evidence. But I believe it is a topic worth exploring.

In normal contexts, non-linear thinking is often superficially referred to as a general "style of thinking" that considers multiple directions of solutions and makes many connections among a variety of reference information. While this loosely defined concept has been applied in business and education through certain models or indexes, so far, I believe the conceptualization of the term is insufficient, let alone examining its cognitive mechanism.

Tracing (being aware of each step in) a process of thinking may appear harder than the formulation of the thought itself. It does not have to be a relatively complex thought to see this, for example, try to trace back step by step how you came to understand the meaning of this sentence. It seems that the mind uses a different approach when "showing" the results of thoughts to itself (being aware) compared to when the thinking occurs.

Humans are able to make quite accurate estimations in a very short period of time without going through detailed reasoning. There are examples in mundane social interactions, such as deciding when to tell what joke to which friend during a conversation for the optimal expected result. Many people may call this type of short-cut thinking "intuition" (another insufficiently conceptualized term).

In my opinion, serendipity - discussed in contexts of innovation (Napier \& Vuong, 2013) - can be the key to exploring the mechanism of (actual) non-linear thinking. The structure of serendipity shows a "jump" in terms of information processing, where consistent observations (tracing/ awareness) cannot be made continuously from the initial problem to the final solution due to a gap in-between. From the observer's perspective, the "jump" is not only applicable to the connections (lines) but also to the problems or solutions (endpoints) as well.

Recent studies in neuroscience show multidimensional processing in terms of neuronal structure and activity in the brain (Gothard, 2020; Stringer et al., 2019). Here, non-linear thinking should be viewed as simultaneous processing multiple values and converging into an observable result (thought) - with the same properties described in the multi-filtering process of the Mindsponge framework (Q. H. Vuong, 2016; Q. H. Vuong \& Napier, 2015). The properties of the observed results can be categorized based on the directionality (active/controlled or "automatic" thinking) of the process as well as the pre-perception toward the result (expected or unexpected). Whichever the case, I argue that non-linear thinking is not a "style of thinking" as portrayed in common understanding nor any extraordinary thinking mode, but rather a natural mechanism of information processing in the brain, regardless of the degree of nonlinearity deemed by the 
observer. Probably the conversion to easily observable linear expressions in the process of tracing/observing thinking require additional calculation power and thus makes it appear difficult.

While the value of serendipity as a strategic advantage is still on the way to becoming confirmed (Q.-H. Vuong, 2021), I look at another value of serendipity: a sign pointing toward an interesting new approach toward the age-old question: how do we think?

Update: More detailed discussions in the full book "A New Theory of Serendipity: Nature, Emergence and Mechanism" (see References).

\section{References}

Gothard, K. M. (2020). Multidimensional processing in the amygdala. Nature Reviews Neuroscience, 21(10), 565-575. https://doi.org/10.1038/s41583-020-0350-y

Napier, N., \& Vuong, Q. H. (2013). Serendipity as a Strategic Advantage? In T. Wilkinson (Ed.), Strategic Management in the 21st Century (pp. 175-199). Westport, CT: Praeger/ABC-Clio.

Stringer, C., Pachitariu, M., Steinmetz, N., Reddy, C. B., Carandini, M., \& Harris, K. D. (2019). Spontaneous behaviors drive multidimensional, brainwide activity. Science, 364(6437), eaav7893. https://doi.org/10.1126/science.aav7893

Vuong, Q. H. (2016). Global Mindset as the Integration of Emerging Socio-Cultural Values Through Mindsponge Processes: A Transition Economy Perspective. In J. Kuada (Ed.), Global Mindsets: Exploration and Perspectives (pp. 109-126). Routledge. https://doi.org/10.4324/9781315736396-8

Vuong, Q. H., \& Napier, N. K. (2015). Acculturation and global mindsponge: An emerging market perspective. International Journal of Intercultural Relations, 49, 354-367. https://doi.org/10.1016/j.ijintrel.2015.06.003

Vuong, Q.-H. (2021). Is it now time to remove that question mark? [Preprint]. Open Science Framework. https://doi.org/10.31219/osf.io/fq3tv

Quan-Hoang Vuong. (2022). A New Theory of Serendipity: Nature, Emergence and Mechanism. Berlin, Germany: De Gruyter. 